\title{
Under the Armenian sky-for development and interchange of experiences
}

\author{
Ewelina Gradzka \\ Pontifical University of John Paul II, Cracow, Poland
}

\section{Introduction}

Under the Armenian sky was an educational project run in cooperation between two partners: Polish Association Under the common sky and Byurakan Astrophysical Observatory (BAO) in 2018/2019. Although, the project's name suggests it was related strictly to Armenia it was connected to a larger initiative run by the Association Under the common sky based on its leading idea, experience, methodology and knowledge. The Association's fundamental aim is "popularization of the cutting-edge knowledge about the Universe as well as teaching skills using modern technology like Stellarium program and telescopes. It is also inspired by the Ancient Greek ideas of arête, paideia and theoria which give a more humanistic component to the project. It is believed that in the excess of contemporary focus on STEM subjects it is important to remember about humans unique capacity to contemplate the reality that surrounds them. This enriches them as reasonable human beings who desire to know just for the sake of it. Surprisingly, such an attitude gives positive results and participants of the project appreciate this" (Gradzka, 2019).

\section{History}

The two organizations had a first chance to meet on 11th March 2016 when Polish coordinator of projects and its main author Ewelina Gradzka came for a preparatory visit to Armenia in search for partners. Sona Farmanyan and Areg Mickaelian were the hosts and represented BAO. During that event Mrs Gradzka had an opportunity to discover the greatness of BAO, its people and its history. Mrs Farmanyan and Mr. Mickaelin organized a meeting with the staff who was introduced to the main features of the project, its objectives, requirements and plan of work. The project had already been running in Kyrgyzstan with a considerable success and it was recomendable to use that experience in Armenia which possess such a long and spectacular astronomical heritage naming at least the work of Viktor Ambartsumian. Additionally, the perspective of cooperation seemed attractive for the two organizations as both sides could share and gain valuable experience. The Association could share the experience of its direct work with teachers' trainings and engagement with astronomy clubs in schools whereas the Observatory as large academic institution could share its experience with science camps for children, astronomy conferences and international engagement in the Office of Astronomy for Development of the International Astronomical Union. Nevertheless, the project did not received funding. At that moment also Georgia was considered a partner country and was represented by Ilia State University and Abastumani Astrophysical Observatory.

The second phase of the cooperation could be considered invitation of Mrs. Gradzka to the International Conference "Astronomical Heritage of the Middle East" held on 13-17 November 2017 at the Armenian National Academy of Sciences in Yerevan. During that event Mrs. Gradzka shared the experience of running projects in Kyrgyzstan and the importance and effectiveness of developmental help if correctly prepared and engaging directly with the improvement of human capital in her speech: "Under the Kyrgyz sky- from astronomy to development". (Gradzka, 2019) A new meeting during the conference motivated both sides to try again and apply for the project dedicated this time entirely to Armenia. 


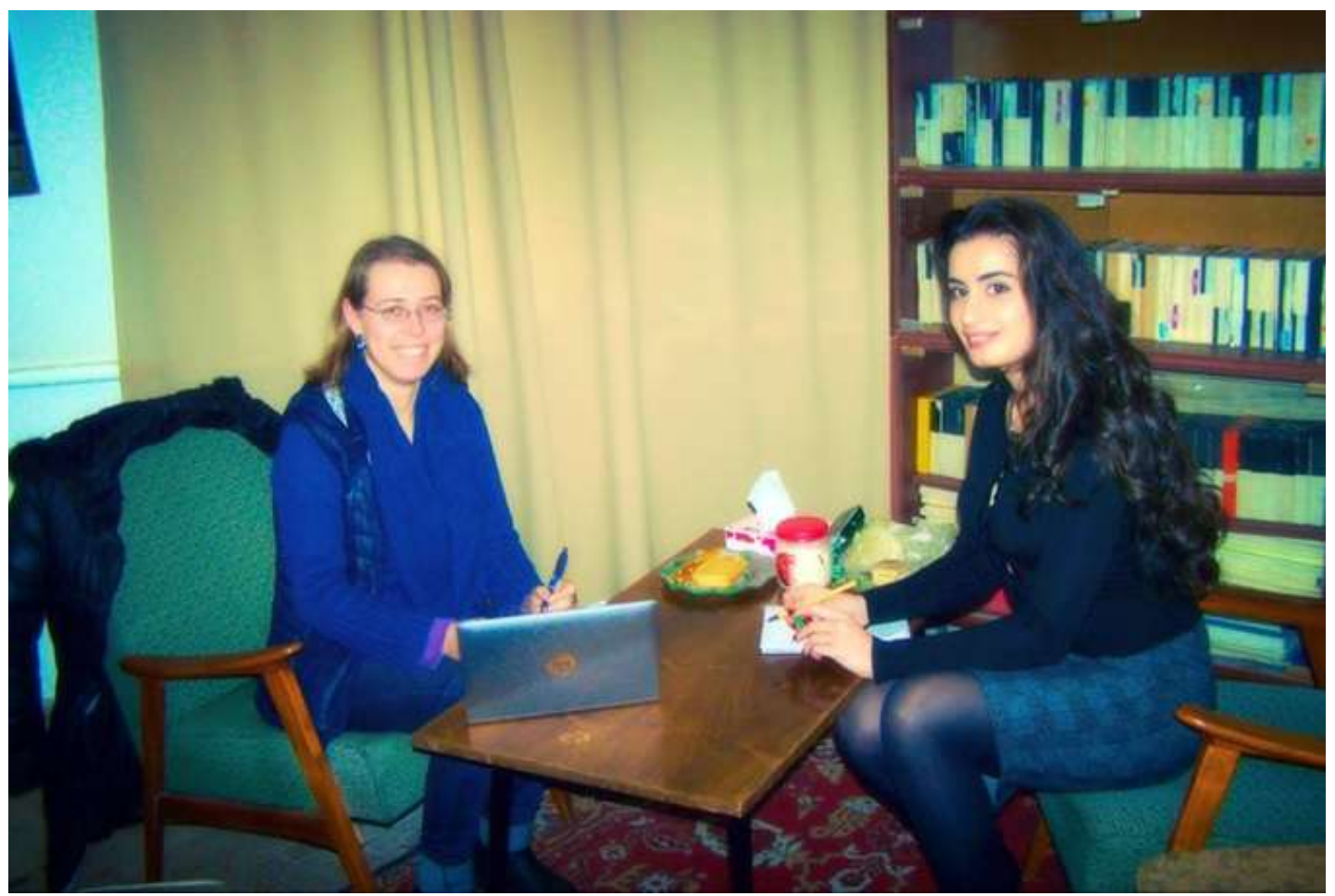

Figure 1. Preparatory meeting for the project of Mrs. Ewelina Gradzka and Mrs. Sona Farmanyan, 11th March 2016, BAO.

Finally, the project Under the Armenian sky was accepted and granted financial support by the Polish Foundation 'Education for Democracy' from their grant program RITA-region in transition.

\section{Astronomy and democracy}

A difficulty among specialists in political science exist in precisely defining what democracy really is. The concept is vague and wide and in different countries it is practiced with a variety of methods (some would be considered undemocratic in other countries like having a king or a queen, being fined for not participating in the elections, or even usage of ID). However, some key elements can be distinguished and among them we can name:

1) "political system for choosing and replacing the government through free and fair elections;

2) the active participation of the people, as citizens, in politics and civic life;

3) protection of the human rights of all citizens;

4) a rule of law, in which the laws and procedures apply equally to all citizens". (Diamond, 2020)

Interesting for the purpose of the project is point number two which relates democracy directly to the idea of civil society. Often, democracy is reduced to the idea of free election and free press but there is a much deeper aspect of it. It requires ordinary people to engage on all levels from school and local community until governmental. There is even more to that. It is claimed that democratic system is beneficial for the character of people. According to philosophers like John Stuart Mill or Jean-Jacques Rousseau it makes people stand up for themselves. Hence, it encourages autonomy of a person. "When they participate in making decisions, they have to listen to others, they are called upon to justify themselves to others and they are forced to think in part in terms of the interests of others". (Christiano,, 2018) Obviously, democracy has also weaknesses as Plato complained that it undermines expertise that is necessary to govern and favors those who are skillful in rhetoric and persuasion. He also undermined the idea that majority of people are capable of thinking good enough to make proper decisions. 
In the project democracy is understood in relation to these ideas. Therefore, it focuses on development of:

- communication and teamwork,

- empowerment of people,

- critical thinking skills,

- access to information and ability to use it,

- organizational skills,

- volunteering and work for local community.

The project aims at preparing children for democracy so to refute in practice Plato's arguments.

\section{Experience}

The Association Under the common sky has been running their projects since 2015 when the first one was launched in Kyrgyzstan ${ }^{1}$. It has been focusing on post- Soviet countries due to the common experience of Poland and ex-member states of Soviet Union. However, it does not limit the idea of the project to that particular region. It simply determines present activity restricted also by the possibility of founding financial support for the projects.

Since 2015 there have been 9 independent projects related to teacher training and establishment of astronomy clubs as well as 7 one-week astrocamps for most active participants of the clubs. In total in the projects have participated 73 astroclubs, 119 teachers have been trained, and approximately 1405 school children have engaged in the clubs and 350 took part in the camps ${ }^{2}$. The project has already been organised in four countries- Kyrgyzstan, Poland, Armenia and Tadjikistan and is going to take place in Uzbekistan.

The Association has worked with various types of partners which gives additional value to the universality and flexibility of the project. The partners have been:

- ngo related to Catholic Church mission- Svet lubvi, Kyrgyzstan;

- ecological and cultural heritage ngo- Institute for Sustainable Development, Kyrgyzstan;

- engineering ngo- Foundation for Innovative and Sustainable Technology, Tajikistan;

- democracy building ngo- Institute for Youth Development, Kyrgyzstan;

- academic institutions- Byurakan Astrophysical Observatory, Armenia and University of Central Asia, Tajikistan;

- public school- State secondary school named after Mirzo Ulugbek, Uzbekistan

This shows that astronomy as a tool for improvement of human life can be used in various context. Additionally, the unique experience of those partners enriched the project with different insights and attitudes into local problems and the Association's management skills.

\footnotetext{
${ }^{1}$ In 2015 the project was officially run by another organization (Dom Spotkań im. Angelusa Silesiusa), but by the same team that since 2016 has organized all the projects in the name of the Association Under the common sky.

${ }^{2}$ These numbers are approximate as in many cases the number of engaged in the work of the clubs was changing during the school year and in some cases exceeding the required min. 15, sometimes in one school there were two groups divided by language, eg. Kyrgyz and Uzbek or Kyrgyz and Russian.
} 
Table 1.

\begin{tabular}{|c|c|c|c|c|c|}
\hline $\mathbf{N}$ & Title & Year & $\begin{array}{l}\text { No. of school } \\
\text { (astroclubs) }\end{array}$ & No. of teachers & $\begin{array}{l}\text { Approx. no. } \\
\text { of students }\end{array}$ \\
\hline 1. & $\begin{array}{l}\text { Under the Kyrgyz } \\
\text { sky ed. I, II, III }\end{array}$ & $\begin{array}{c}2015, \\
2016 / 2017, \\
2017 / 2018\end{array}$ & 15 & 30 & 300 \\
\hline 2. & $\begin{array}{l}\text { Under the common } \\
\text { sky -Poland }\end{array}$ & 2016 & 10 & 20 & 150 \\
\hline 3. & $\begin{array}{l}\text { Under the Kyrgyz } \\
\text { sky-on the camp } \\
\text { (ed. I, II, III, IV) }\end{array}$ & $\begin{array}{l}2016 \\
2017 \\
2018\end{array}$ & 10 & 11 & 350 \\
\hline 4. & $\begin{array}{c}\text { Under the Kyrgyz sky in } \\
\text { the Kashubian region }\end{array}$ & 2017 & 1 & 1 & 50 \\
\hline 5. & $\begin{array}{l}\text { Astrojailoo- under the } \\
\text { Kyrgyz sky-astronomy } \\
\text { for development and } \\
\text { biocultural diversity }\end{array}$ & 2018 & 5 & 10 & 75 \\
\hline 6. & Under the Armenian sky & $2018 / 2019$ & 10 & 20 & 150 \\
\hline 7. & $\begin{array}{c}\text { Astronomy for } \\
\text { development of civil } \\
\text { competencies of } \\
\text { schoolchildren ed. I \& II, } \\
\text { Kyrgyzstan }\end{array}$ & $\begin{array}{l}2018 / 2019 \\
2019 / 2020\end{array}$ & 12 & 17 & 180 \\
\hline 8. & Under the Tadjik sky & $2019 / 2020$ & 10 & 10 & 150 \\
\hline 9. & Under the Uzbek sky ${ }^{3}$ & $2020 / 2021$ & $(6)$ & $(12)$ & $(90)$ \\
\hline & SUMMARY & 2015-2019 & $73(79)$ & $119(131)$ & 1405(1495) \\
\hline
\end{tabular}

\section{Under the Armenian sky}

The core idea of the project run in Armenia (as well as in other countries) had three phases. The first one was related to teachers trainings and provision of equipment. The second one focused on establishment of astronomy clubs by each teacher in their school and in the third phase astroclubs should organize events for local communities. To be able to do so, partner organizations announced an open call for schools with project requirements. Any school that was wishing to participate had to send application form where one of the questions was related to motivation. The next step was to choose together the schools that best fit the project requirements. After that, telescopes were bought for all 10 schools and shipped it from Moscow astronomy shop. Additionally, tools like laser pointers (to run sky observations), football caps with red light (for sky observations), Sky Atlas (with impressive illustrations) were provided. In the first phase, there were two trainings planned. A fourday training took place at BAO on 26-30 July 2018 in the very beginning of the project. The training was divided into two parts: day-time and night-time. During the day (despite scorching heat) there were 9 hours of workshops focused on basic concepts in astronomy starting from solar system, planets, solar activity, stellar evolution, galaxies, constellations. The methodology used was based on hands-on activities with small lectures on particular subjects. Additionally, there was introduction to Stellarium computer program used to simulate night sky (and can be used as simple planetarium) and practice on computers. In the evening, the participants developed their skills in usage of the sky map and telescope which means search for constellations, planets, deep sky objects as well as Moon and Sun observations. Using the opportunity of having a training at professional observatory the teachers paid a visit to the BAO facilities guided by Mrs Anahit Sargsyan. There was also a lecture given by Mr. Areg Mickaelian on his professional research in astronomy. The whole training finished with a final exam to check teachers' readiness to run astronomy clubs on their own. The second three-day 


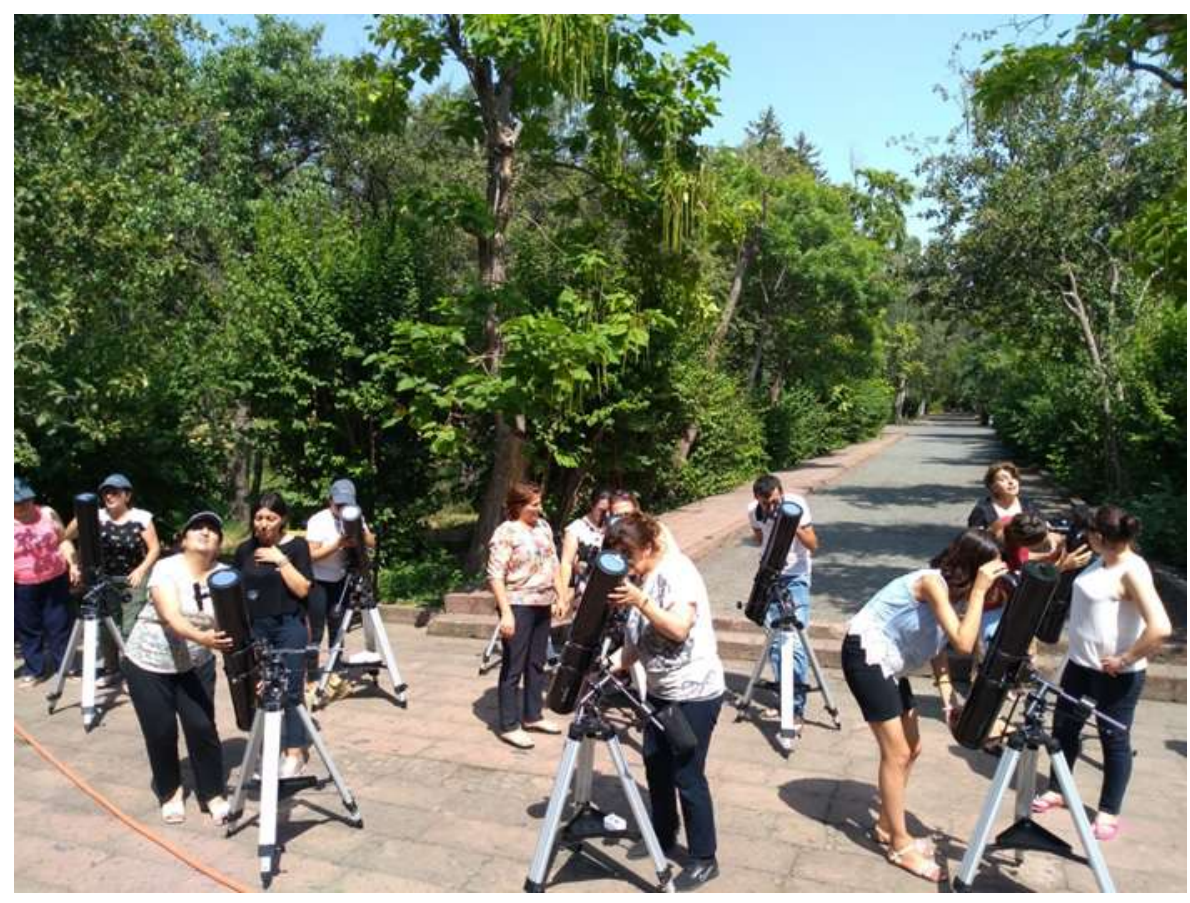

Figure 2. PA four-day teachers' training at BAO on 26-30 July 2018.

training was held on 19-21 April 2019 in the second half of the project ${ }^{4}$. Had the same schedule but different material related to teachers needs stated in evaluation form filled before arrival for the training. Usually, and in this case as well, additional practice of the previously acquired skills is expected and new hands-on activities are presented.

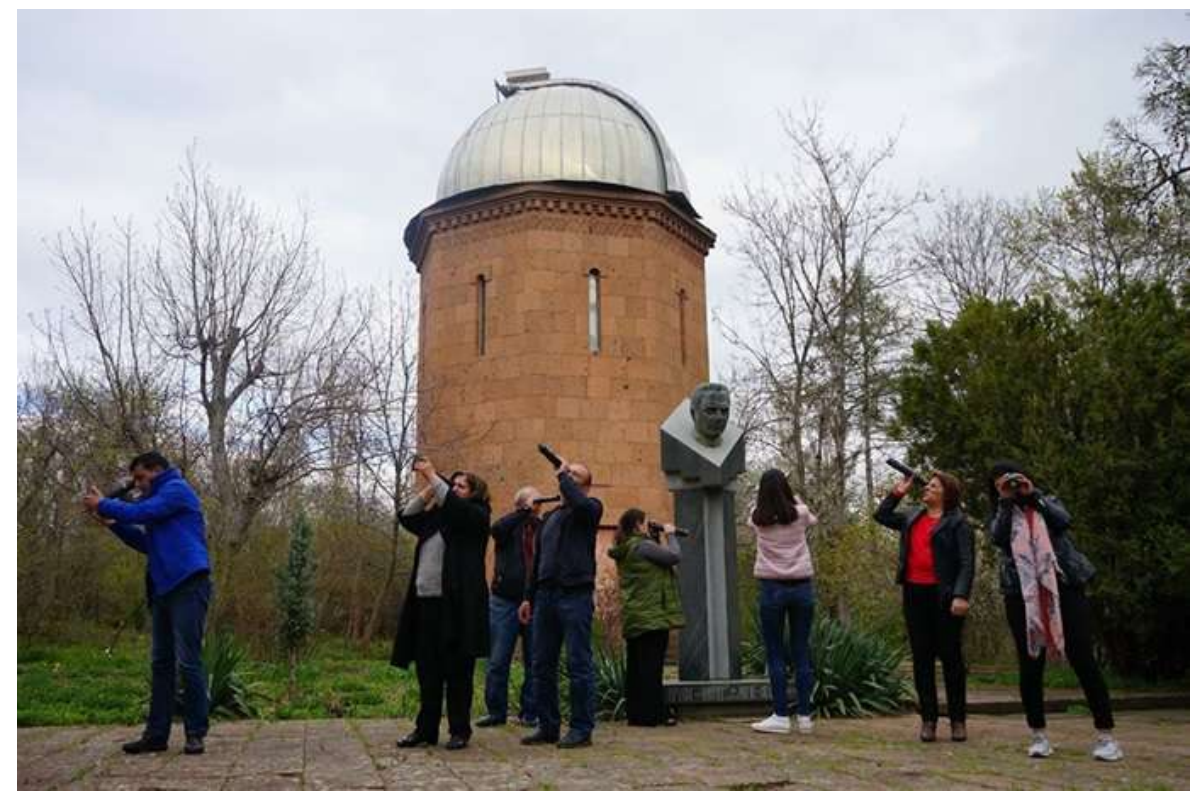

Figure 3. A three-day teachers' training (activity with spectroscopes) at BAO on 19-21 April 2019.

The day time part was run by Mrs. Ewelina Gradzka and night time part by Mr. Tsovak Voskanian. This was the first time a local amateur-astronomer was engaged in the project. Mr. Voskanian proved very professional even though he lacked experience in running trainings for large group of participants (there were 10 telescopes with 20 people to coordinate at the same time). Experience of amateur astronomer like Mr. Voskanian suits better for the training on small telescopes than of professional astronomers. Usually, amateur-astronomer's ability to find deep sky objects and use various types of

${ }^{4}$ The official dates of the project were 01.06.2018 until 31.05.2019. 
telescopes far extends that of professionals.

In the second phase of the project astronomy clubs were run by the trained teachers for students of their schools. Each club was asked to meet twice a month and an exemplary program of the meetings was prepared at the end of the teachers' training based only on the activities presented during the training. Therefore, the teachers who are often new to the subject ${ }^{5}$ are capable of running the clubs for a year without major problems.

At the end of the project, as third phase, which usually coincides with the end of the school year as in case of Under the Armenian sky the clubs were requested to prepare astroevents for local communities.

The major focus of the trainings is to change teachers' attitude to teaching (provide modern, engaging methodology) as well as to their students (develop more partnership relations in the club). These give both, the teacher and the student, a new perspective on learning process where teachers stop to be providers of knowledge and rather accompany students in their development, learning with them and not having to know better all the aspects of the new material (very often students get much better in using Stellarium or telescope then their teachers or surf the Internet for cutting-edge discoveries or technologies that the teacher knows nothing about). This becomes a joint adventure into the wonders of the Universe. On the other hand, it is observed that students appreciate such an attitude and it pays off. It is quite common that in the clubs the most engaged are pupils who before showed no interest for STEM subjects and caused trouble. The students are encouraged to take responsibility for the equipment like the telescope and to collaborate together especially in the preparation of the event for local community. The event is planned to teach students to share their knowledge, skills and enthusiasm and promote volunteer work. The students report that it is a positive challenge for them and it empowers them. This is very motivating when you can stand in front of others and show what you have learnt and what type of interesting, international project you have participated in. Generally, it has to be admitted that astronomy leaves no one indifferent so the task to inspire others is quite easy.

\section{Challenges}

All the projects run by the Association had to face many different challenges that differ among countries and their peculiarities. Nevertheless, at least a group of three main areas can be distinguished. It is teachers, donors and relations with academia.

First of all, challenges related to teachers refer to their relations in school. It is common that either the teacher is engaged in the project but lacks support from the director or the director is interested in the project but the teacher is not and is forced to participate. Another issue is related to the reality of teachers' work. They are overloaded with paper work and tasks, exposed to a lot of stress, earn very small salaries and they lack support from parents (whose children become more and more spoiled and bad-behaved). Nevertheless, the project had teachers who devoted a lot of free time to run the clubs with a lot of passion and engagement. One of them in Armenia is Mrs. Cristina Mkrtumyan from Syunik Gorayk Secondary School. Mrs. Mkrtumyan frequently reported on her advancement of work with her students, prepared with them videos of their events and even after officially the project has finished she continues her work and contact with the Association publishing her students' achievements and night sky observations on Facebook group of the Association.

Another challenge mentioned are donors. It is often difficult to find a donor whose expectations can be met by the project described. It is common that support is more often granted to projects related to infrastructure (building hospitals, schools) or humanitarian needs (like food supply, medicine, clothing). Nowadays, ecology became an important issue as well as support for protection of cultural heritage. Development of human capital is still underestimated. Additionally, very often donors have their specific organizational expectations like they do not allow hiring foreign trainers or require working with inexperienced partners. There are sound reasons for that, however, in many cases work in

\footnotetext{
${ }^{5}$ Even though majority of them are physics teachers they lack good knowledge in astronomy and for sure modern methodology; but there are also sometimes mathematicians, informatics, geography and biology teachers or even history or language teachers- who very often turn out to be the most devoted.
} 


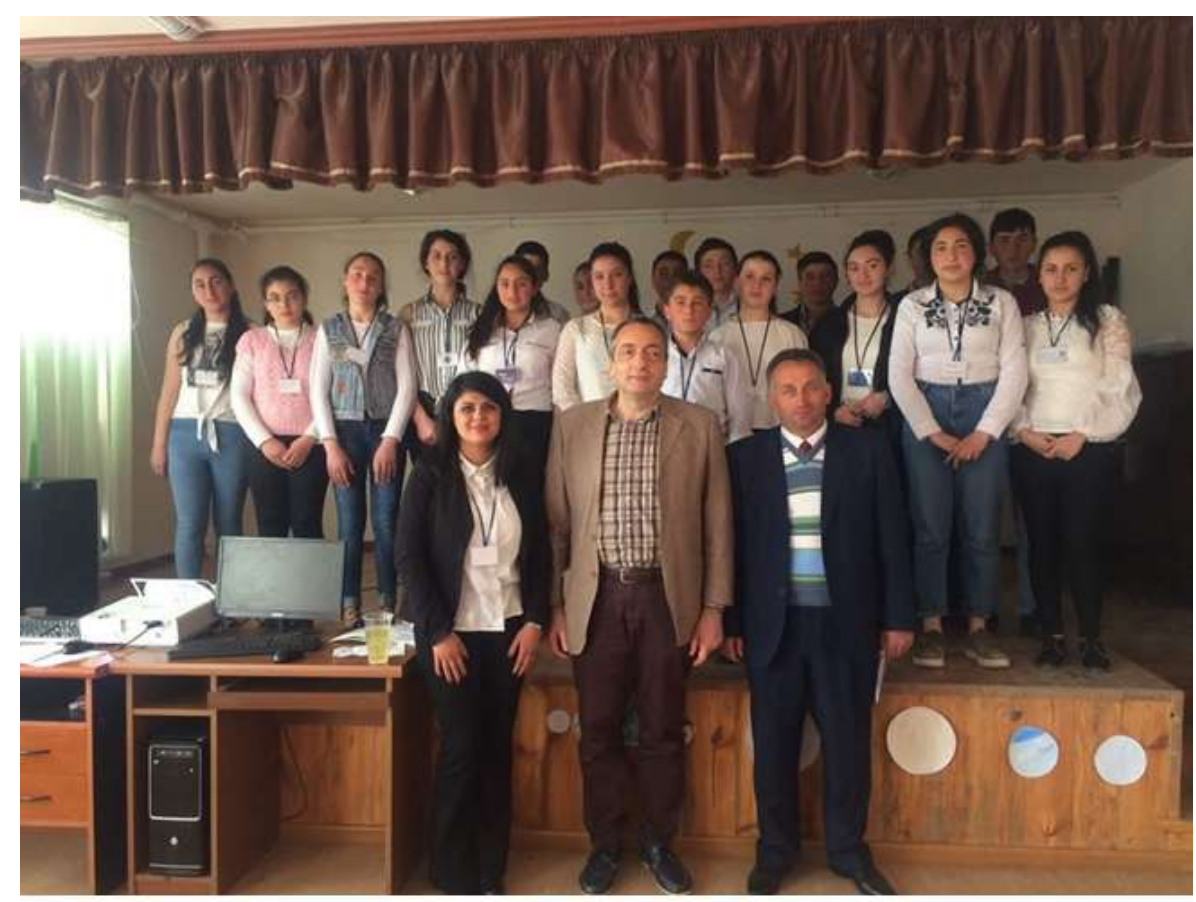

Figure 4. Mr. Areg Mickaelian visiting astronomy club run by Mrs. Cristina Mkrtumyan from Syunik Gorayk Secondary School in 2019.

the field verifies this. Length of projects is also problematic as it requires time to influence change in people's behaviors, attitudes, beliefs or motivations. The Association is trying to respond positively to these problems and one of the method is flexibility in adjusting the core idea to particular expectations of the donors. It is also an enriching task as it guided the project into cooperation in the work on ecology issues (tasks like 'There is not planet B' were added or building solar system from recyclable materials to raise awareness), cultural heritage (creation of new constellations related to local traditions or gathering historical information on astronomy in the region), finding ways to co-finance (then foreign trainers salaries are covered by other organizations) or simply strengthening argumentation skills and gaining knowledge (like investigation of reports on humanitarian and developmental aid) to improve effectiveness in convincing donors to support the projects.

The last challenge worth considering is relation between non-governmental organizations (NGO) and academia (like universities or science institutions). First of all, there is an organizational difference as NGO operates faster and is more flexible whereas large institutions have long administrative path and decisions must be taken in hierarchical order. Work in project requires often a dynamic attitude to the plan and decisions must be taken on the spot. In large institutions also responsibility is blurred. It is difficult to decide whose action failed and why (not to accuse anybody, rather to reflect on improvement in the future). Additionally, there is still underestimation of the work done by the Association in the opinion of large institutions' workers. It has been as issue that NGO competences were undermined and lack of expertise was claimed. Professional science institutions also still do not fully see themselves as collaborators with the society. They follow the role of prestigious science institution which role is to do science and not to engage with the public. In this case, in the first place such experience is evaluated to be used effectively in the future and plan better and much in advance (taking into consideration longer administrative path) as well as more time and consideration are devoted to establish personal relations and respond patiently and with understanding to the doubts and reluctance. It is also recommendable to prepare clear task and responsibility division.

\section{Future}

The future of the project in Armenia depends on schools, teachers and students. They have all the necessary knowledge, skills, equipment and help from the Association as well as BAO to continue 
their work. It is hoped that further projects based on the idea of Under the Armenian sky will be organized but it requires finding other donors and schools and teachers interested in participation.

The Association will continue promoting its flag-ship project and it has been confirmed that the new edition is going to take place in Uzbekistan between 2020/2021. However, due to global coronavirus (COVID-19) pandemia the dates are under consideration. It is hope that in the future the project will reach the rest of post-Soviet countries like Georgia, Ukraine or Kazakhstan. Nevertheless, it is not restricted to this geographic/historic area and it is open for implementation in other parts of the world.

\section{References}

Christiano, T., 2018, Metaphysics Research Lab, Stanford University, https://plato.stanford. edu/archives/fall2018/entries/democracy/,

Diamond L., 2020, https://diamond-democracy.stanford.edu/speaking/lectures/ what-democracy,

Gradzka E., 2019, Astronomical Heritage of the Middle East, Astronomical Society of the Pacific Conference Series. San Francisco: Astronomical Society of the Pacific, pp 285-294 